\title{
Circular differential scattering of light in films of chiral polyfluorene
}

\author{
Girish Lakhwani, Stefan C. J. Meskers, René A. J. Janssen
}

\section{Stokes-Müller approach to selective reflection}

To consider polarization effects by our setup mentioned in the main article, we employ the Stokes-Müller formalism; a given polarization state is completely described by its Stokes vector and any optical element (polarizer, modulator, sample, photodiode) is defined by its $4 \times 4$ Müller matrix. The transformation of a polarization state is given mathematically by premultiplication of the corresponding Stokes vector with the Müller matrix of the optical devices in order of their application in the setup. The Stokes vector for polarized incident light is as mentioned below.

$S_{i}=\left(\begin{array}{l}I_{0} \\ I_{1} \\ I_{2} \\ I_{3}\end{array}\right)$

where $S_{\mathrm{i}}$ is the Stokes vector for incident light, $I_{0}$ is the total intensity, $I_{1}$ is intensity of linear polarization of light at $45^{\circ}, I_{2}$ is intensity of circular polarization of light, and $I_{3}$ is intensity of linear polarization of light at $0^{\circ}$.

The intensity at the photodetector at position 4 in Figure 2 can now be calculated using the equations $S 1$ and $S 2$

$$
\begin{aligned}
& I_{\text {out }}=\text { Modulator }(\text { in }) \times \text { Sample }_{L C} \times \text { Modulator }(\text { out }) \times \text { Pol }_{\text {vertical }} \times \text { Photodiode } \times S_{i} \\
& I_{\text {out }}=\text { Modulator }(\text { in }) \times \text { Sample }_{\text {glass }} \times \text { Modulator }(\text { out }) \times \text { Pol }_{\text {horizontal }} \times \text { Photodiode } \times S_{i}
\end{aligned}
$$

where $S_{\mathrm{i}}$ is Stokes vector for incident vertically polarized light. 
$S_{i}=\left(\begin{array}{l}1 \\ 0 \\ 0 \\ 1\end{array}\right)$

$(S 1)$ and $(S 2)$ contain the Müller matrices for the several optical elements, which are written below.

$$
\operatorname{Pol}_{\text {vertical }}=\frac{1}{2}\left(\begin{array}{cccc}
1 & 0 & 0 & 1 \\
0 & 0 & 0 & 0 \\
0 & 0 & 0 & 0 \\
1 & 0 & 0 & 1
\end{array}\right) \quad P o l_{\text {horizontal }}=\frac{1}{2}\left(\begin{array}{cccc}
1 & 0 & 0 & -1 \\
0 & 0 & 0 & 0 \\
0 & 0 & 0 & 0 \\
-1 & 0 & 0 & 1
\end{array}\right)
$$

Modulator(in) $=\frac{1}{2}\left(\begin{array}{cccc}1 & 0 & 0 & 0 \\ 0 & 1 & 0 & 0 \\ 0 & 0 & C(\delta, t) & -S(\delta, t) \\ 0 & 0 & S(\delta, t) & C(\delta, t)\end{array}\right) \quad$ Modulator(out $)=\frac{1}{2}\left(\begin{array}{cccc}1 & 0 & 0 & 0 \\ 0 & 1 & 0 & 0 \\ 0 & 0 & C(\delta, t) & S(\delta, t) \\ 0 & 0 & -S(\delta, t) & C(\delta, t)\end{array}\right)$

$$
\text { Photodiode }=\left(\begin{array}{llll}
1 & 0 & 0 & 0 \\
0 & 0 & 0 & 0 \\
0 & 0 & 0 & 0 \\
0 & 0 & 0 & 0
\end{array}\right)
$$

where $C(\delta, t)$ and $S(\delta, t)$ are given by $\cos (\delta(\sin (2 \pi f t)) / 2)$ and $\sin (\delta(\sin (2 \pi f t)) / 2)$ respectively, and represent the periodic change of retardation in the quartz crystal of the modulator. $\delta$ is the amplitude of the modulation, which can be adjusted by controlling the voltage of the circuit that drives the modulator. $f$ denotes the natural frequency of the modulator $(50 \mathrm{kHz})$ and t represents time.

The Müller matrices describing the reflection by the LC film and by glass with refractive index $n$ are given by: 
Sample $_{L C}=\frac{1}{2}\left(\begin{array}{cccc}1 & 0 & 1 & 0 \\ 0 & 0 & 0 & 0 \\ 1 & 0 & 1 & 0 \\ 0 & 0 & 0 & 0\end{array}\right) \quad$ Sample $_{\text {glass }}=\left(\frac{1-n}{1+n}\right)^{2}\left(\begin{array}{cccc}1 & 0 & 0 & 0 \\ 0 & 1 & 0 & 0 \\ 0 & 0 & -1 & 0 \\ 0 & 0 & 0 & 1\end{array}\right)$

These matrices are derived from the general Müller matrix describing the optical properties of a (optically thin) sample (J. Schellman, H.P. Jensen Chem. Rev. 1987, 87, 1359):

$$
\text { Sample }=f\left(\begin{array}{cccc}
1 & -L D^{\prime} & C D & -L D \\
-L D^{\prime} & 1 & -L B & -C B \\
C D & L B & 1 & -L B^{\prime} \\
-L D & C B & L B^{\prime} & 1
\end{array}\right)
$$

Here, $f$ is a factor describing the reflectivity of the sample.

Table S1. Comparison between experimental $g_{\text {scat }}$ and $g_{\text {trans }}$ values of annealed film of polyfluorene 1 (1.1 $\mu \mathrm{m}$ thick prepared by doctor blading) at different wavelengths for different film orientations. $g$-Values are calculated according to Eq. (2) and (6).

\begin{tabular}{|c|c|c|c|c|}
\hline \multirow{2}{*}{$\begin{array}{c}\text { Wavelength } \\
\text { (in nm) }\end{array}$} & \multicolumn{4}{|c|}{ Polyfluorene Film } \\
\cline { 2 - 5 } & \multicolumn{2}{|c|}{$g_{\text {scat }}\left(\times 10^{-2}\right)$} & \multicolumn{2}{c|}{$g_{\text {trans }}\left(\times 10^{-2}\right)$} \\
\cline { 2 - 5 } & polymer side & glass side & polymer side & glass side \\
\hline 458 & -3.7 & -3.8 & 2.5 & 2.6 \\
\hline 476 & -3.6 & -4.0 & 1.8 & 1.6 \\
\hline 488 & -3.0 & -4.0 & 1.2 & 1.0 \\
\hline 542 & -5.0 & -5.0 & 1.5 & 1.5 \\
\hline 632 & -3.3 & -3.0 & 1.5 & 1.4 \\
\hline
\end{tabular}


Table S2. Optical rotation measured at the Na-D line for films of polyfluorene 1 prepared by doctor blading and the cholesteric liquid crystalline film mentioned in the main text.

\begin{tabular}{|c|c|c|}
\hline Samples & Conditions & $\begin{array}{c}\text { Rotation } \\
\text { (deg.) }\end{array}$ \\
\hline Reference & Air & -0.002 \\
\hline \multirow{2}{*}{ PF } & Unannealed & -0.07 \\
\cline { 2 - 3 } & Annealed $120^{\circ} \mathrm{C}$ & -0.22 \\
\cline { 2 - 3 } & Annealed $200^{\circ} \mathrm{C}$ & -0.37 \\
\hline ChLC & Red reflecting & 13.2 \\
\hline
\end{tabular}

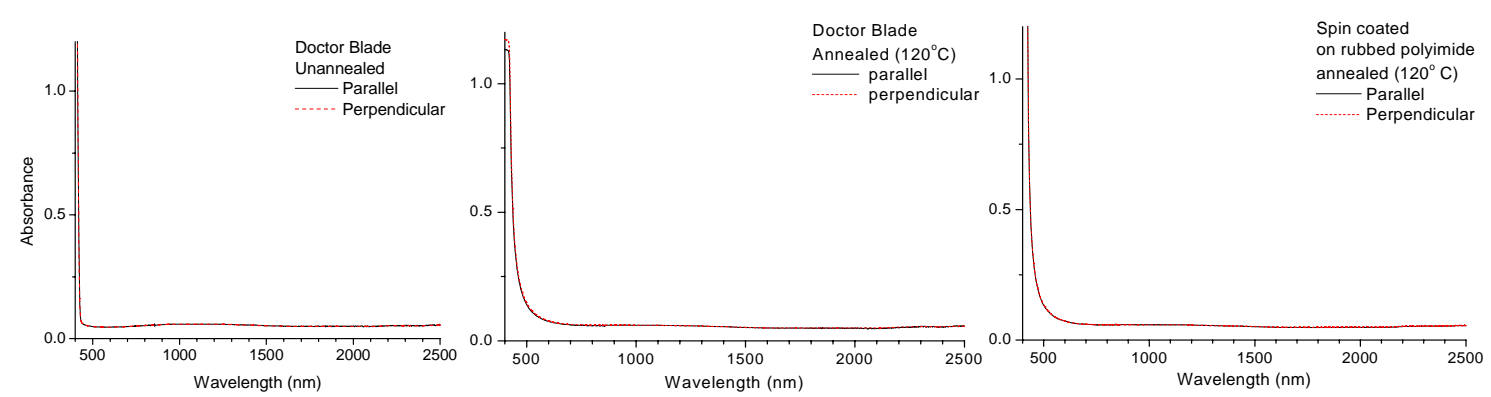

Figure S1: Linear polarized absorption of a film of 1 prepared by doctor blading on plane glass before (left panel) and after thermal annealing (middle) or prepared by spin coating on a rubbed polyimide layer and subsequent annealing at $120{ }^{\circ} \mathrm{C}$ (right). The polyimide alignment layer (70 nm thick) was spin coated at $6000 \mathrm{rpm}$ on glass substrates and was further soft baked at $80{ }^{\circ} \mathrm{C}$ for $15 \mathrm{~min}$. The polyimide coated glass substrates were rubbed against a nylon cloth. On top of this polyimide, a layer of polyfluorene was spin coated from chloroform solution (30 g/L) and annealed at $120{ }^{\circ} \mathrm{C}$ for 2 hours.

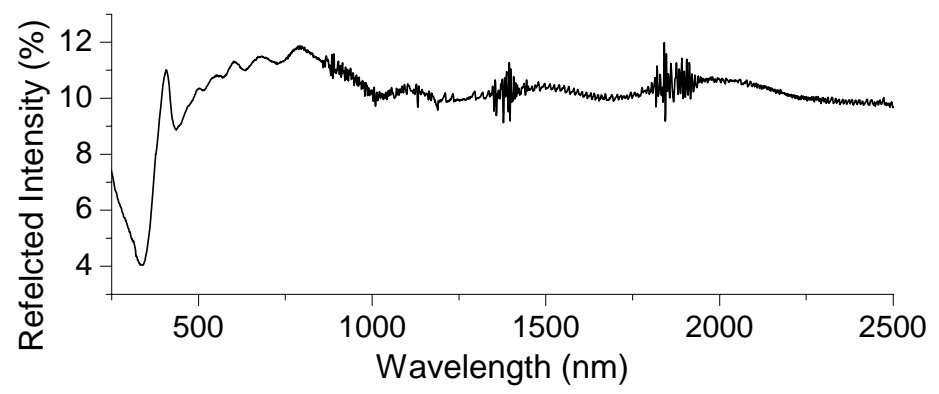

Figure S2 Specular reflection spectrum of a film of $\mathbf{1}$ prepared by doctor blading on plane glass and thermal annealing at $120{ }^{\circ} \mathrm{C}$. Film thickness: $1.1 \mu \mathrm{m}$. 


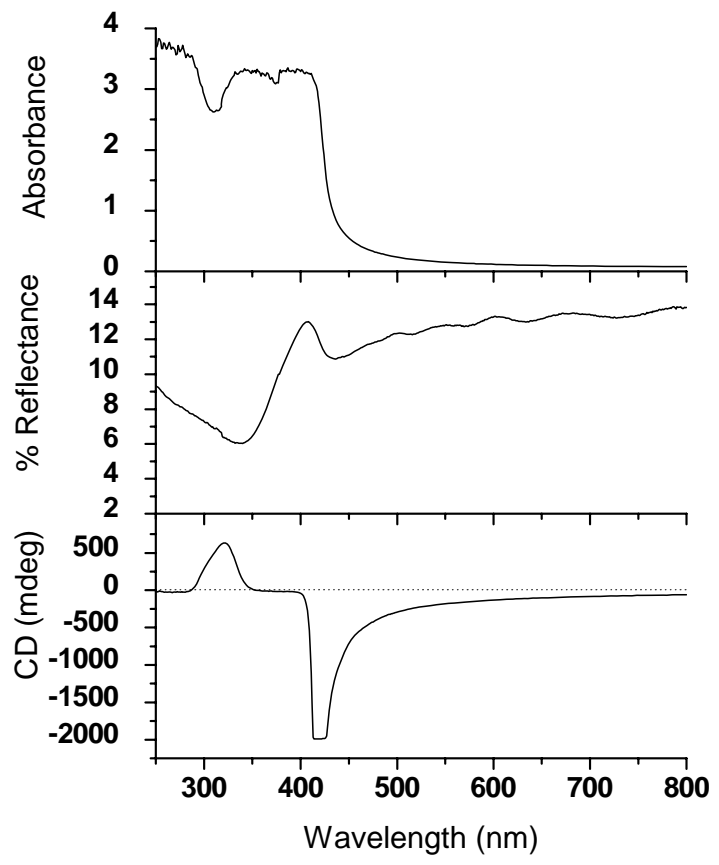

Figure S3. Absorbance, reflection and CD spectra for a film of 1 prepared by doctor blading and thermal annealing at $200{ }^{\circ} \mathrm{C}$ for $2 \mathrm{~h}$. Film thickness $1.2 \mu \mathrm{m}$.

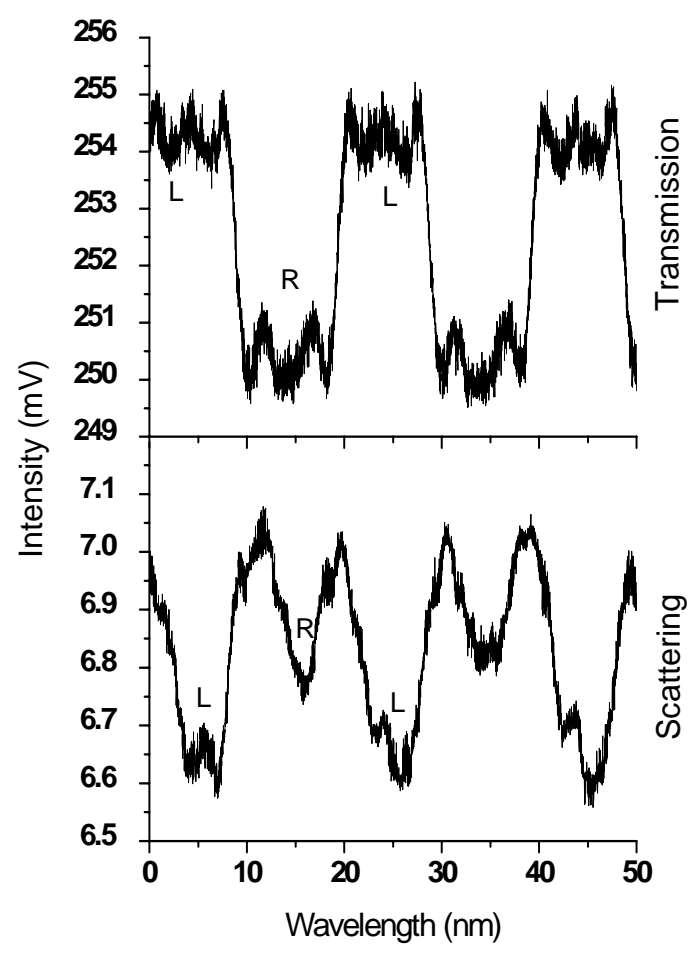

Figure S4. Intensity-time curves for transmitted (upper) and scattered (lower) light for a film of 1 prepared by doctor blading and thermal annealing at $200{ }^{\circ} \mathrm{C}$ for $2 \mathrm{~h}$. at $543 \mathrm{~nm}$ 


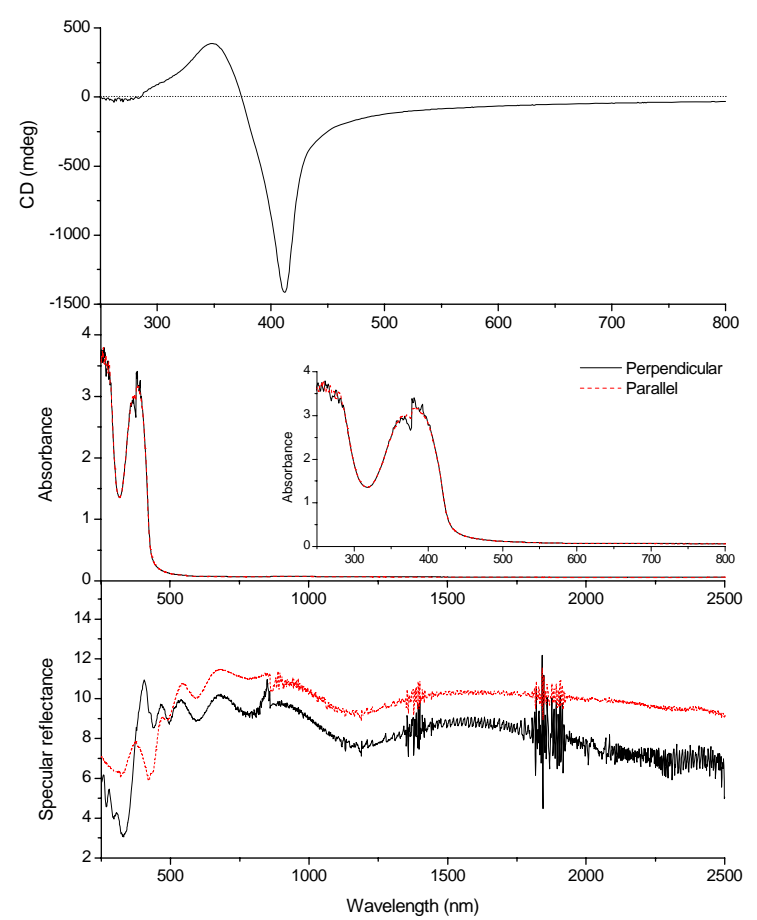

Figure S5. Circular dichroism, absorbance and specular reflectance of a film of polyfluorene $\mathbf{1}$, spin coated on a rubbed polyimide layer and annealed at $120^{\circ} \mathrm{C}$, for 2 hours.

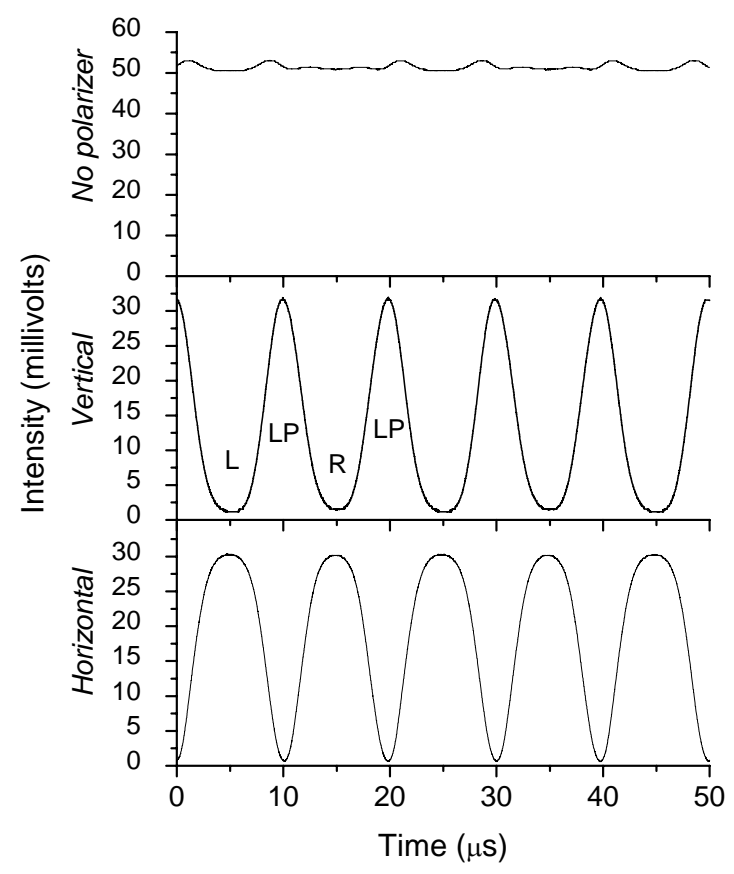

Figure S6. Reflection measurements on a film of polyfluorene 1, spin coated on a rubbed polyimide layer and annealed at $120{ }^{\circ} \mathrm{C}$ (Figure S5). Wavelength: $543 \mathrm{~nm}$. See also legend Figure 4. 